\section{MODIFICATION OF CUTTING TOOLS BY DRAG FINISHING} JOZEF PETERKA, PETER POKORNY, STEFAN VACLAV, BORIS
PATOPRSTY, MAREK VOZAR

Slovak University of Technology in Bratislava, Faculty of Materials Science and Technology in Trnava, Institute of Production Technologies, Trnava, Slovak Republik

DOI : 10.17973/MMSJ.2020_03_2019130

jozef.peterka@stuba.sk

The paper deals with a progressive method of modification of cutting tools by drag finishing process. The subject of the research is the dependence of the drag finishing time on the size of the cutting edge radius. The milling tool - solid cemented carbide mill was made on a tool grinder REINECKER WZS 60. The cutting tool was drag finished on the OTEC DF-3 TOOLS drag finishing machine. The measurements of cutting edge radius was performed on two devices: 3D optical microscope ALICONA Infinite focus G5 and contour and surface measuring machine ZEISS SURFCOM 5000. The results of the measurements are evaluated at the end of the paper.

KEYWORDS tool wear, cutting edge radius, cutting edge preparation, drag finishing

\section{INTRODUCTION}

Today's trend is to increase productivity and reduce machining costs. Durability testing is also related to the production of tools and their use. These tests are carried out by different methods [Monková 2018]. Wear tests in combination with other methods of surface microstructure monitoring are also carried out [Neslušan 2018]. Quality tools save companies money and ensure accurate machining. For high productivity, tools are technologically modified and micro geometry and surface are also modified. To achieve longer durability it is important to use cutting edge preparation to modify the cutting edge [Zlámal 2018]. One of the methods for modification the radius of the cutting edge is drag finishing process. The objective here is to stabilize the cutting edge. With brittle materials such as carbide, a sharp edge tends to flake and wear quickly, especially when under a heavy load. Simply rounding the cutting edge to approx. $15 \mu \mathrm{m}$ considerably stabilizes the edge and significantly increases tool life and reliability. The drag finishing and stream finishing machines enable edges to be rounded in a completely reliable process to specific values in the $\mu \mathrm{m}$ range [Rounding 2019]. The drag finishing process can also be used after coating the tools achieving higher surface quality resulting in longer durability of the coating which allows for higher tool life [Zlámal 2019].

\section{MATERIAL AND METHODS}

The solid cemented carbide mills made of cemented carbide with grade of CTS20D by the Ceratizit Company (K20-K40 by ISO) were used in this article. This cemented carbide material with content of Co of $10 \%$ and $90 \%$ of WC and achieved hardness of 1600 by Vickers. As a workpiece for manufacturing the solid cemented carbide mills was used cemented carbide rod. The Wire Electrical Discharge Machining method was used to make workpieces with dimension $\varnothing 10 \mathrm{~h} 6 \times 110 \mathrm{~mm}$.

\subsection{Solid cemented carbide tools grinding}

The solid cemented carbide mills will be used for milling difficult-to-cut materials, especially for austenitic stainless steel. Cutting edge preparation process was carried out on these solid cemented carbide mills to round the sharp cutting edge. Grinding machine Reinecker WZS 60 was used for manufacturing solid cemented carbide mills. Four grinding wheels from synthetic diamond by the producer URDIAMANT Slovakia s.r.o. were used to manufacture the tools. Grain size of grinding wheels was D64 by ISO 6106, which means that the average grain size was from $50-62 \mu \mathrm{m}$. Different grinding wheels were used to manufacture the flute of the tool and also the face of the tools (Table 1). NUMROTOplus software was used to create NC code for grinding machine.

\begin{tabular}{|c|cc|c|}
\hline $\begin{array}{c}\text { Grinding } \\
\text { wheels } \\
\text { type }\end{array}$ & $\begin{array}{c}\text { Diameter } \\
{[\mathrm{mm}]}\end{array}$ & $\begin{array}{c}\text { Spindle } \\
\text { rotation speed } \\
{\left[\mathrm{min}^{-1}\right]}\end{array}$ & $\begin{array}{c}\text { Grinding feed } \\
\text { rate [m.min }\end{array}$ \\
\hline 1V1 & 100 & 3634 & 19.02 \\
\hline $1 \mathrm{~A} 1$ & 75 & 3634 & 14.21 \\
\hline $11 \mathrm{~V} 9$ & 100 & 4750 & 29.29 \\
\hline 12 V9 & 125 & 3058 & 20 \\
\hline
\end{tabular}

Table 1. Grinding wheels used to grinding process

The geometry of solid cemented carbide mills was following: Diameter of the tool $-9.947 \mathrm{~mm}$, core diameter $-4.893 \mathrm{~mm}$, helix angle $28.190^{\circ}$, Rake angle (on the face) $-7.78 \mathrm{~mm}$, rake angle (on the face) $2-15.78$, flank angle $-7.56^{\circ}$, rake angle (on the helix) $-9.07^{\circ}$. The grinding process is shown in Figure 1

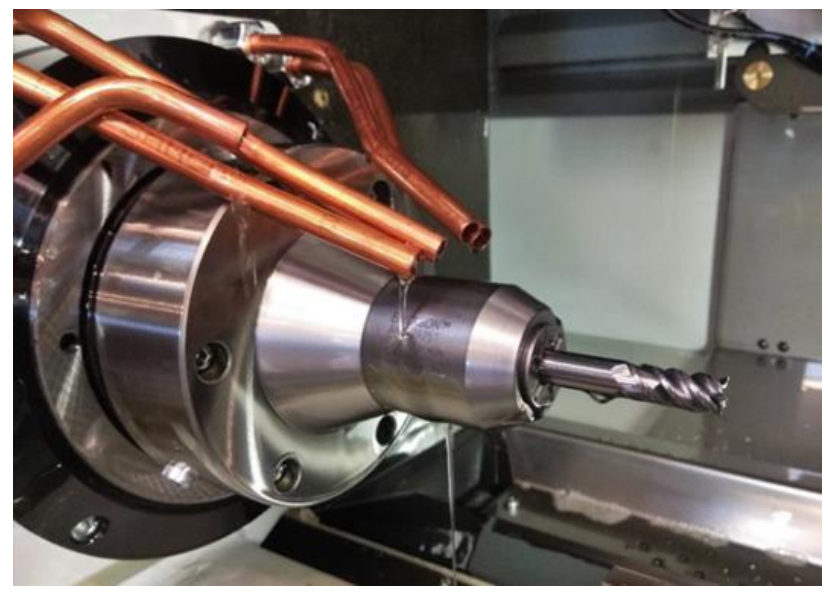

Figure 1. Grinding process of solid cemented carbide mills

\subsection{Drag finishing process and measuring the cutting edge radius}

Cutting edge preparation was used to make the rounded cutting edge of solid cemented carbide mills. Drag finishing was chosen for edge preparation and the drag finishing machine was by German producer OTEC model DF-3 Tools. Grinding granulate OTEC SIX 70/16 with OTEC HL 06 grinding oil was used for drag finishing process. Ten tools were drag finished with the time of 10 minutes, while every minute was one of the tool taken out of the machine, so the first tool was drag finished for one minute and tenth tool was drag finished for 10 minutes. Every solid cemented carbide mill was drag finished half of the time clockwise and other half of the time counterclockwise. After cutting edge preparation the cutting edge 
radius was measured and evaluated and after that, next batch of ten solid cemented carbide mills was also drag finished in order to verify the size increase of the cutting edge radius. Drag finishing process is shown in Figure 2.

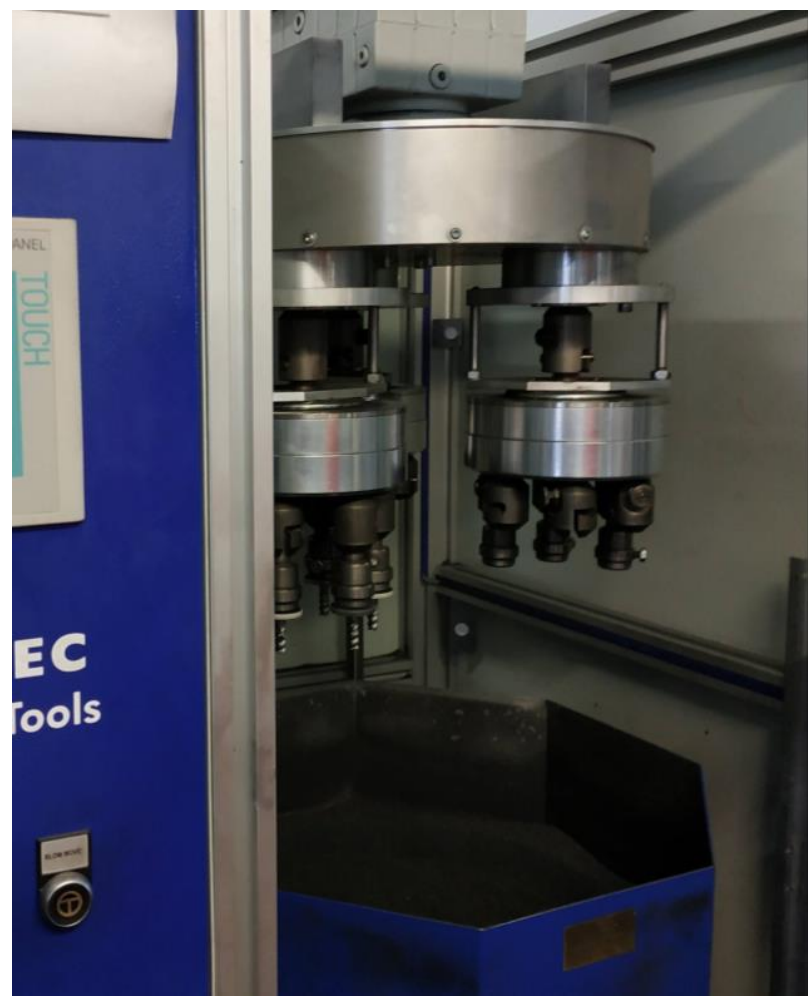

Figure 2. Drag finishing of solid cemented carbide mills

Two measuring machines were used in this research - 3D optical microscope Alicona Infinite focus G5 with measuring software Edge Master and the contour and surface measuring machine ZEISS Surfcom 5000. First ten solid cemented carbide mills were measured on ALICONA measuring machine. Cutting edge radius was measured one millimetre from the tip of the tool on the end of the tool. Another ten mills were measured on Zeiss measuring machine. Measuring of solid cermet carbide is shown in Figure 3.

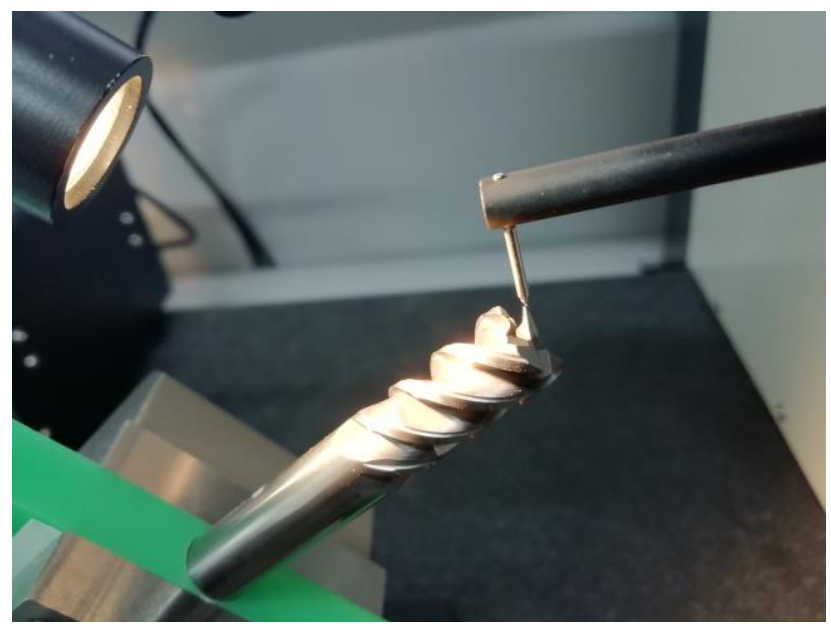

Figure 3. Measuring on ZEISS SURFCOM 5000

\section{RESULTS AND DISCUSSION}

Solid cemented carbide mills were grinded on Reinecker WZS 60 grinding machine, then drag finished on OTEC DF-3 Tools and the size of cutting edge radius was measured on ZEISS Surfcom 5000 and ALICONA Infinite focus G5. The aim was to evalute the dependce of drag finishing time on cutting edge radius. During the first experiment, the solid cemented carbide mills were measured in one minute intervals of drag finishing. Example of measurement on Alicona is shown in Figure 4.

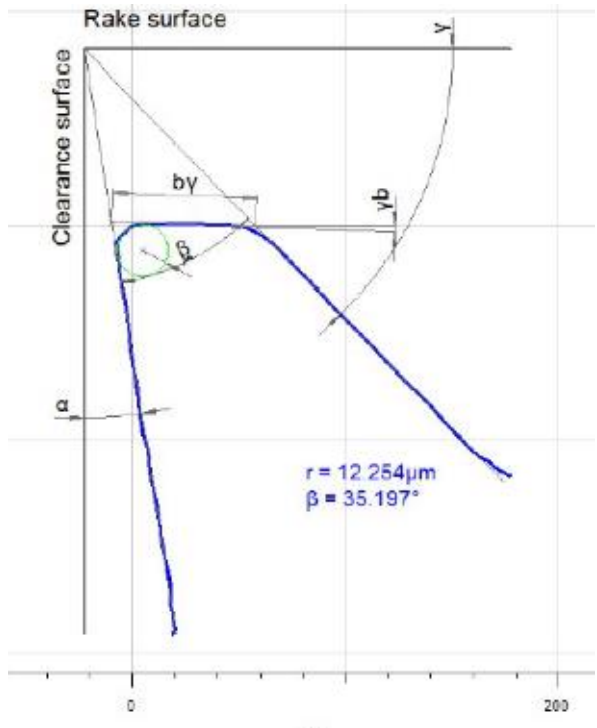

Figure 4. Example of measurement protocol of cutting edge on Alicona

After first experiment, the size of cutting edge radius was only $15 \mu \mathrm{m}$, so the authors try to increase the size of cutting edge radius by increasing the drag finishing time. The drag finishing time was increased to 100 minutes and the solid cemented carbide mills were measured in intervals of 10 minutes. This measurement was carried out on ZEISS Surfcom 5000 machine. Example of measurement on ZEISS is shown in Figure 5.

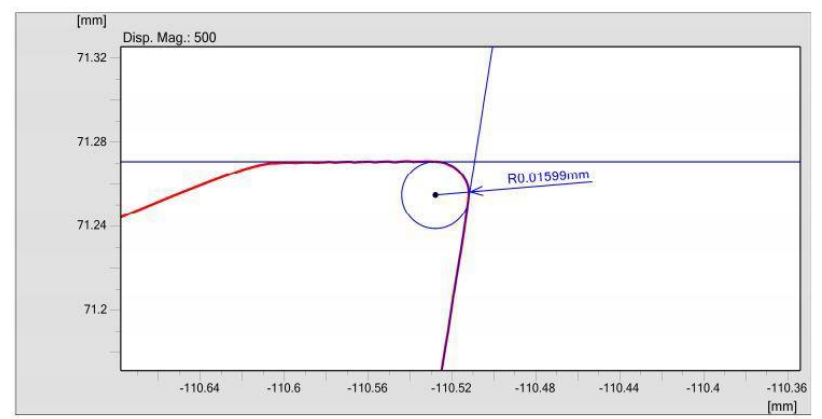

Figure 5. Example of measurement protocol of cutting edge on ZEISS

There were two measured ares of the size of the cutting edge radius. Figure 6 shows that the first area was on joined teeth on the face of the mill and second area was on the short teeth on the face of the mill. 

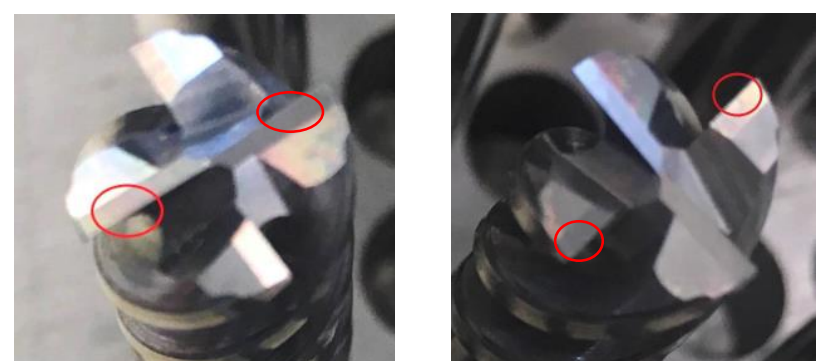

Figure 6. Measurement areas of the solid cemented carbide mills After measurement the results were evaluated and they were plotted into a graph of dependence of drag finishing time on size of cutting edge radius. Dependence of drag finishing on the size of the cutting edge radius is shown in Figure 7.

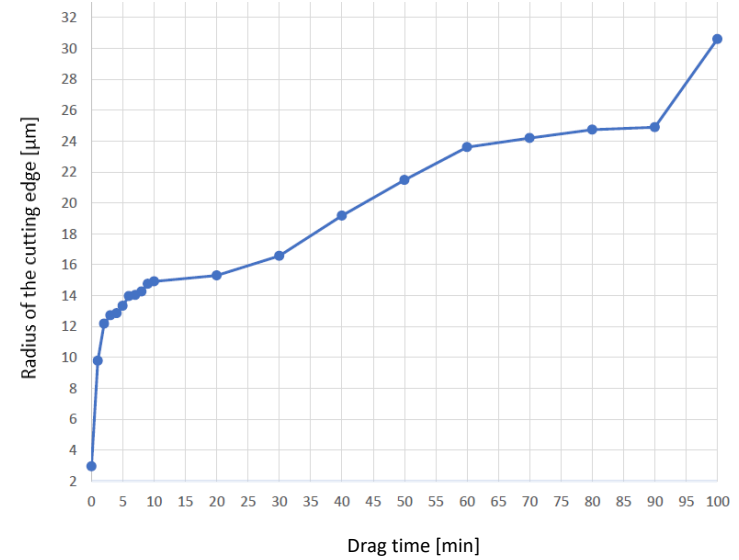

Figure 7. Dependence of drag finishing on the size of the cutting edge radius

Fig 8. shows the following zones:

* Zone from 0 to $10 \mathrm{~min}$ - sharp increase of cutting edge radius.

* Zone from 10 to $90 \mathrm{~min}$ - a relatively linear increase of cutting edge radius.

* Zone from 90 to 100 min - sharp increase of cutting edge radius.

\section{CONCLUSIONS}

Purpose of the experiment described in this article was to investigate the dependence of drag finishing time on the size of the cutting edge radii on the face teeth of the solid cemented carbide mills. After manufacturing the tools by grinding, they were drag finished while the size of the edge radii was periodically measured. Average measured values were used for plotting graphs describing the dependence of cutting edge radii on multiple areas of the tool teeth. The development of the dependence had very similar character for all the measured areas. In general, during the first ten minutes of the drag finishing, the cutting edge radius was increasing steadily in an almost linear fashion. After passing this first phase, increase of the cutting edge radius stabilized and became considerably slower. After 10 minutes the size of cutting edge radius was approximately $15 \mu \mathrm{m}$ and when the drag finishing time was 100 minutes the size of cutting edge radius increased only to size 30 $\mu \mathrm{m}$. The reason why the size of the cutting edge radius did not increase over $30 \mu \mathrm{m}$ is because of the grinding granulate. OTEC - the producer of this granulate recommends this granulate for producing the size of cutting edge radius up to value of $30 \mu \mathrm{m}$. By conducting this experiment, we have verified the importance of the time of drag finishing process and described its influence on the achieved cutting edge radii. Results of the experiment will be used for further research of drag finishing parameters and their influence on the final size and shape of cutting edge radii of solid cemented carbide tools. In the following research we will focus on the influence of the cutting edge radius on other parameters of the cutting process. These are for example cutting forces, torque and surface quality given by the surface roughness parameter Ra.

\section{ACKNOWLEDGMENTS}

This work was supported by the Scientific Grant Agency of the Slovak Republic under the grant no. 1/0097/17 and the Slovak Research and Development Agency of the Slovak Republic under the Contract no. APVV-16-0057.

\section{REFERENCES}

[Monkova 2018] Monkova, K., et al. Tool life investigation of the thread making tools. Manufacturing Technology, October 2018, Vol. 18, No.5., pp 787-792. ISSN 1213-2489

[Neslusan 2018] Neslušan, M., et al. Influence of tool wear on surface state after turning stainless steels. Manufacturing Technology, October 2018, Vol. 18, No.5., pp 793-798. ISSN 1213-2489

[Rounding 2018] Rounding. Rounding of cutting edges. OTEC Präzisionsfinish GmbH, 2019, Germany, [online]. [4. 11. 2019]. https://www.otec.de/en/finishing-processes/rounding/ [Zlamal 2018] Zlámal, T., et al. The influence of microgeometry of cutting tool on dynamic load of system. In: METAL 2018 27th International Conference on Metallurgy and Materials, Conference Proceedings 2018, Brno, May, 2018, TANGER Ltd. pp 1795-1800. ISBN 978-808729484-0

[Zlamal 2019] Zlámal, T., et al. The Influence of Surface Treatment of PVD Coating on Its Quality and Wear Resistant. In: Coatings 2019, 9(7), 439;

https://doi.org/10.3390/coatings9070439

\section{CONTACTS:}

Prof. Dr. Ing. Jozef Peterka

Slovak University of Technology in Bratislava,

Faculty of Materials Science and Technology in Trnava,

Institute of Production Technologies,

Ulica Jána Bottu č. 2781/25, 91724 Trnava, Slovak Rrepublic

e-mail: jozef.peterka@stuba.sk

Doc. Ing. Peter Pokorny, PhD. 
Slovak University of Technology in Bratislava,

Faculty of Materials Science and Technology in Trnava,

Institute of Production Technologies,

Ulica Jána Bottu č. 2781/25, 91724 Trnava, Slovak Rrepublic

e-mail: peter.pokorny@stuba.sk

Doc. Ing. Stefan VAclav, PhD.

Slovak University of Technology in Bratislava,

Faculty of Materials Science and Technology in Trnava,

Institute of Production Technologies,

Ulica Jána Bottu č. 2781/25, 91724 Trnava, Slovak Rrepublic

e-mail: stefan.vaclav@stuba.sk

Ing. Boris Patoprsty

Slovak University of Technology in Bratislava,

Faculty of Materials Science and Technology in Trnava,

Institute of Production Technologies,

Ulica Jána Bottu č. 2781/25, 91724 Trnava, Slovak Rrepublic

e-mail: boris.patoprsty@stuba.sk

Ing. Marek Vozar

Slovak University of Technology in Bratislava,

Faculty of Materials Science and Technology in Trnava,

Institute of Production Technologies,

Ulica Jána Bottu č. 2781/25, 91724 Trnava, Slovak Rrepublic

e-mail:marek.vozar@stuba.sk 